\title{
Hypermethylation of tumor-suppressor gene CpG islands in small-cell carcinoma of the urinary bladder
}

\author{
Phillip H Abbosh ${ }^{1}$, Mingsheng Wang ${ }^{1}$, John N Eble ${ }^{1}$, Antonio Lopez-Beltran ${ }^{2}$, \\ Gregory T MacLennan ${ }^{3}$, Rodolfo Montironi ${ }^{4}$, Suqin Zheng ${ }^{1,5}$, Chong-Xian Pan ${ }^{6}$, \\ Honghong Zhou ${ }^{7}$ and Liang Cheng ${ }^{1,8}$
}

\begin{abstract}
${ }^{1}$ Department of Pathology, Indiana University, Indianapolis, IN, USA; ${ }^{2}$ Department of Pathology, Cordoba University, Cordoba, Spain; ${ }^{3}$ Department of Pathology, Case Western Reserve University, Cleveland, OH, USA; ${ }^{4}$ Institute of Pathological Anatomy and Histopathology, School of Medicine, Polytechnic University of the Marche Region (Ancona), United Hospitals, Ancona, Italy; ${ }^{5}$ Department of Pathology, North China Coal Medical College, Tangshan, China; ${ }^{6}$ Department of Medicine, Division of Hematology/Oncology, University of California at Davis, Sacramento, CA, USA ; ${ }^{7}$ Division of Biostatistics, Indiana University, Indianapolis, IN, USA and ${ }^{8}$ Department of Urology, Indiana University, Indianapolis, IN, USA
\end{abstract}

\begin{abstract}
Small-cell carcinoma of the urinary bladder (SCBC) is a rare tumor, which shows a common clonal origin with urothelial carcinoma. It bears a high metastatic potential, even when discovered in a localized state. Identifying the molecular underpinnings of this disease may elucidate useful clinical information regarding prevention, diagnosis, prognosis, treatment, and surveillance. As DNA methylation is widely recognized as having a pivotal role in the process of carcinogenesis, we analyzed the DNA methylation status of four frequently hypermethylated tumor suppressors in small-cell and transitional-cell carcinoma (TCC) arising concomitantly in 13 patients. Fourteen cases of pure TCC were also included in the analysis. We identified frequent methylation of RASSF1 and MGMT and infrequent methylation of MLH1 and DAPK1 in cases of concomitant TCC and SCBC. Similar rates of methylation were found in pure and concomitant histopathologies, with the exception of MGMT, which was much less frequently methylated in pure TCC. These findings suggest that SCBC and TCC have common origins, establish DNA methylation of some tumor suppressors as frequent occurrences in both histopathologies, and suggest that MGMT methylation may be an SCBC-specific epimutation.
\end{abstract}

Modern Pathology (2008) 21, 355-362; doi:10.1038/modpathol.3801012; published online 11 January 2008

Keywords: urinary bladder; small-cell carcinoma; DNA methylation; epigenetics

DNA methylation-induced silencing of gene expression is now recognized as an important contributor in all stages of carcinogenesis. ${ }^{1}$ Methylation of CpGdense regions, or $\mathrm{CpG}$ islands (CpGIs), associated with the first exons of many genes, serves to recruit transcriptional silencing machinery, including methyl-CpG-binding proteins, histone deacetylases and methyltransferases, and ATP-dependent chromatin-remodeling enzymes. ${ }^{2,3}$ Silencing of key tumor and metastasis suppressors, ${ }^{4,5}$ drug-metabo-

Correspondence: Dr L Cheng, MD, Department of Pathology and Laboratory Medicine, Indiana University School of Medicine, 350 West 11th Street, Clarian Pathology Laboratory Room 4010, Indianapolis, IN 46202, USA.

E-mail: lcheng@iupui.edu

Received 7 May 2007; revised 10 October 2007; accepted 11 October 2007; published online 11 January 2008 lizing enzymes, ${ }^{6}$ and DNA-repair proteins ${ }^{7}$ is an event that contributes to carcinogenesis, acquisition of invasiveness and metastatic potential, angiogenesis, and therapy refractoriness. DNA methylation is a target for both therapeutic and biomarker purposes. ${ }^{8}$ Importantly, the study of DNA methylation in clinical samples may provide useful and novel insights into the pathobiology of disease processes such as cancer.

Transitional-cell carcinoma (TCC) arises from urothelium, which lines the bladder, as well as the renal pelvis, ureter, and portions of the urethra. Although infrequent in occurrence, small-cell bladder cancer (SCBC) may evolve or co-evolve from pre-existing TCC. $^{9}$ We hypothesized that DNA methylation of specific genes may underlie the pathogenesis of SCBC. In this study, we quantitatively analyzed the methylation status of RASSF1, 
MLH1, DAPK1, and MGMT, in cases of SCBC, which coexisted with TCC. These genes are tumor suppressors that are commonly methylated in malignancies of many tissues in humans. In addition, MLH1 was chosen because of its known role in mismatch repair pathway, ${ }^{7,10-12}$ which is known to govern sensitivity to platinum based therapies, which are part of the typical chemotherapy regimen for TCC. We were able to separately assess the CpGI methylation status in synchronous SCBC and TCC in 13 patients.

\section{Materials and methods}

\section{Sample Selection and Preparation}

Tissues from 13 patients with transitional-cell (urothelial) carcinoma (TCC) concurrent with small-cell carcinoma of the urinary bladder were included in our study. Archival materials were retrieved from the surgical pathology files of the participating institutions. Clinical and pathological information was available for all the patients. Patients ranged in age from 63 to 83 years, with a mean age of 73 years. Eleven patients were pathological stage pT2 and two were pathological stage pT3. Tumors were diagnosed by light microscopy, with each case fulfilling the criteria established for urothelial carcinoma and small-cell carcinoma, according to the World Health Organization classification system. ${ }^{13}$ For pathological staging, the 2002 tumor, lymph node, and metastasis (TNM) classification system was used. ${ }^{14}$ Tissues were microdissected and DNA was extracted as previously described..$^{9,15}$ This research was approved by the Indiana University Institutional Review Board.

In addition, 14 patients with pure TCC were analyzed in comparison. All these patients had advanced-stage (pT2 or above) and high-grade bladder cancer.

\section{Bisulfite Conversion of Genomic DNA}

Before conversion, a quantitative PCR reaction was performed using $2 \mu$ l of genomic DNA as template, to ensure that $>400 \mathrm{pg}$ of DNA was present in the extracted sample. This was accomplished using the eukaryotic elongation factor $1 \alpha$ gene $(E E F 1 A 1)$ in a Taqman ${ }^{\mathbb{R}}$-based assay (primer sequences in Table 1, CG dinucleotides in boldface). DNA was treated with bisulfite as described previously. ${ }^{16}$ Converted DNA was purified using Zymo Spin IC Columns (Zymo Research, Orange, CA, USA) as described by the manufacturer. DNA was eluted with $20 \mu \mathrm{l}$ of sterile water.

\section{Quantitative Methylation-Specific PCR}

Quantitative methylation-specific PCR (qMSP) is a TaqMan-based assay based on conventional MSP. ${ }^{17}$ 
Two microliters of bisulfite-converted DNA were used as template in $20-\mu \mathrm{l}$ qMSP reactions. Reactions were optimized for each reactant in separate control reactions before the study, and contained $1 \times$ PCR buffer, $8.75 \mathrm{mM} \mathrm{MgCl}_{2}, 0.3 \mathrm{mg} / \mathrm{ml}$ BSA, $125 \mathrm{nM}$ forward and reverse primers, $100 \mathrm{nM}$ probe, $62.5 \mu \mathrm{M}$ each dNTP, and $0.5 \mathrm{U}$ of Platinum Taq (Invitrogen, Carlsbad, CA, USA). Primers were synthesized by MWG (High Point, NC, USA). Probes were modified by $5^{\prime}$ FAM and $3^{\prime}$ TAMRA. Primer and probe sequences, GenBank accession numbers, and amplicon locations are listed in Table 1 and are previously described. ${ }^{18}$ PCR was performed for 50 cycles using the Light Cycler machine (Roche, Indianapolis, IN, USA). Each set of PCR reactions included positive and negative controls. Negative controls used were blanks (water) or non-bisulfitetreated DNA. Second-derivative maximum points were used to quantitate samples. All samples were referenced to an empty fluorescence channel to reduce background signal. To quantitate sample values, linear regressions were constructed using serial dilutions of a known amount of DNA (before bisulfite treatment), which was methylated in vitro using enzyme SssI (New England Biolabs, Ipswitch, MA, USA). A minimum threshold of detection for methylation of each gene was empirically determined using control DNA. This threshold was reproducibly $20-100 \mathrm{pg}$ of fully methylated normal human male genomic DNA (Promega, Madison, WI, USA) for each primer. Reactions with an amount of template less than the reliable minimal detectable threshold amplified products erratically on different days. Therefore, sample scores were deemed positive or negative for gene methylation based on this threshold. This prevented the need for an internal quantitative control.

\section{Statistical Analysis}

Methylation of RASSF1, MGMT, and MLH1 in TCC, SCBC, and normal tissues was compared using McNemar's exact test for matched pairs. The association between methylation in TCC and SCBC tissues was also analyzed across RASSF1 and $M G M T$ by investigating methylation of both $R A S S F 1$ and MGMT, and methylation of either RASSF1 or $M G M T$, using McNemar's exact test. The association between pathological stage and gene methylation was examined by Fisher's exact test. All $P$-values were two-sided and a $P$-value $<0.05$ was considered statistically significant.

\section{Results}

Tissues were microdissected for DNA isolation (Figure 1). Amplifications using the RASSF1 qMSP primers were performed on standardized samples and all tissues used in the study (Figure 2a and b). A linear regression for RASSF1 primers was con-
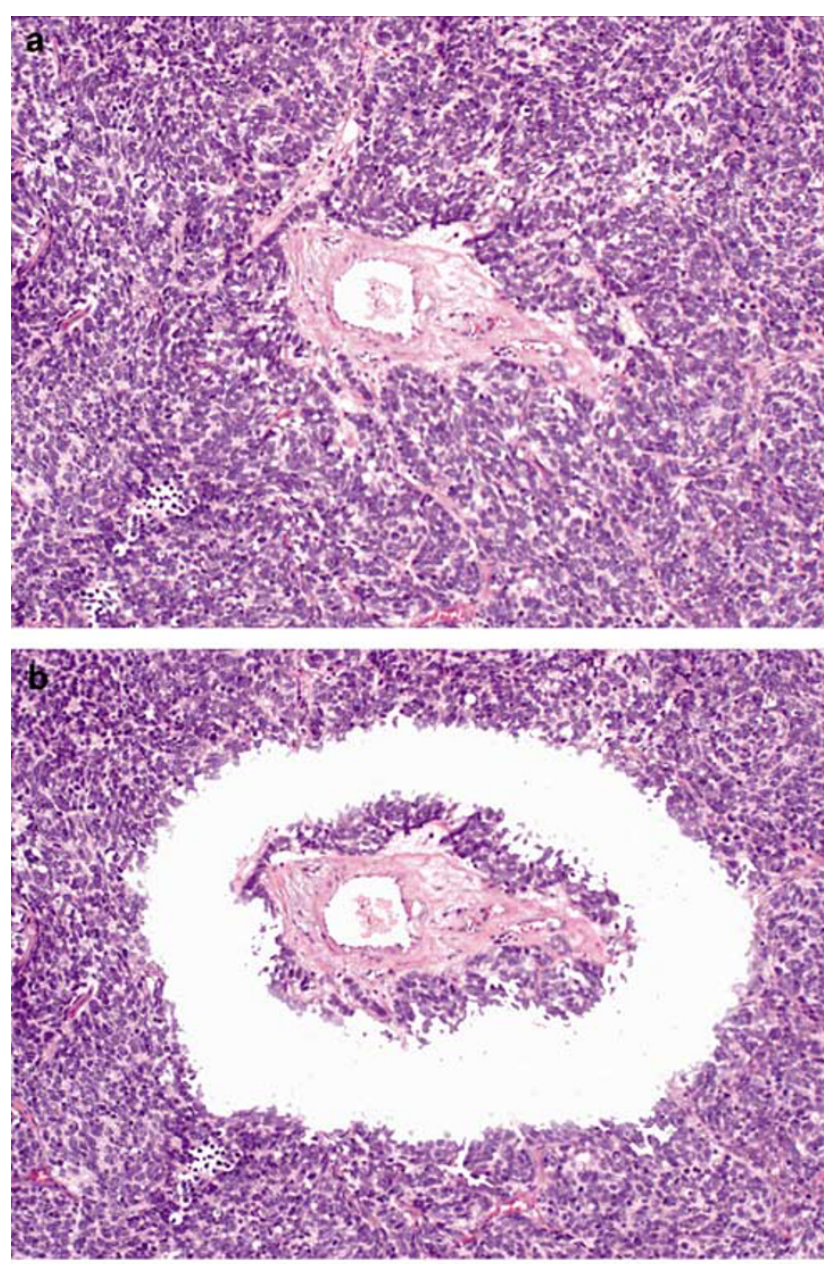

C

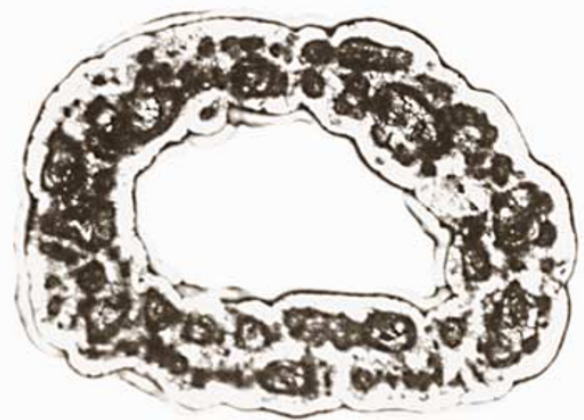

Figure 1 Laser-capture microdissection of small-cell carcinoma of the urinary bladder. Hematoxylin and eosin-stained sections showed small-cell carcinoma before microdissection (a) and after microdissection (b). (c) Laser-captured tumor cells.

structed (Figure 2c). MGMT, DAPK, and MLH1 primers produced similar slopes and intercepts after linear regressions were constructed for each primer (data not shown).

All 13 TCC tissues (associated with coexisting small-cell carcinoma) selected for this study showed methylation of at least one gene (Table 2). Twelve of 13 SCBC samples showed methylation of at least one gene, and 12 of 13 TCC samples showed methylation 

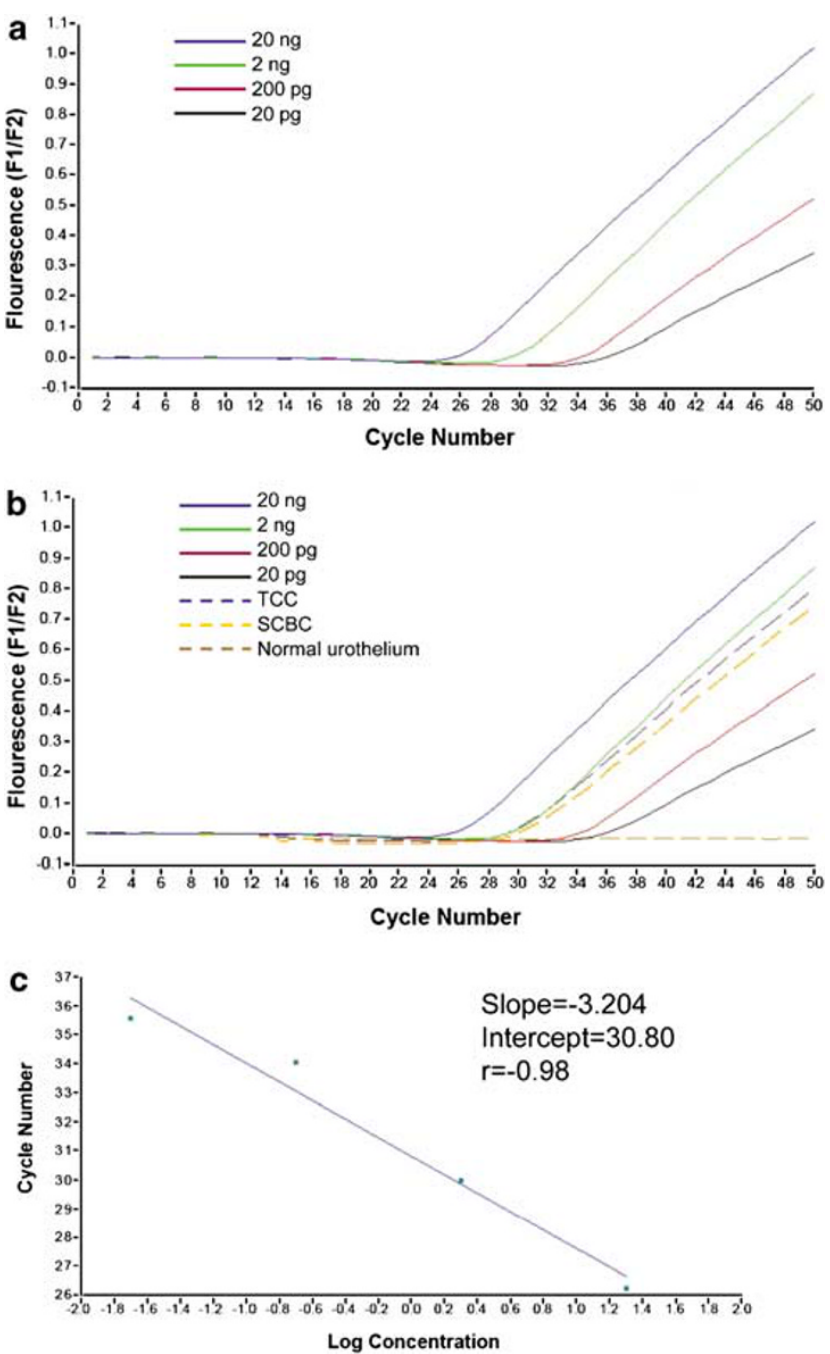

Figure 2 (a) Known amounts of in vitro methylated, bisulfitetreated DNA were amplified using RASSF1 qMSP primers. (b) Fluorescence/amplification curves for selected tissues used in this study are shown. (c) A linear regression was constructed from the second-derivative maximum points for each standard. Other primer/probe sets used in the study produced similar slopes and $y$-intercepts.

of at least one gene. Three TCC tissues showed methylation of both RASSF1 and MGMT, and six SCBC tissues showed methylation of both RASSF1 and MGMT. Only one tissue (an SCBC) showed methylation of three or more genes.

RASSF1 methylation was observed in $46 \%$ (6 of 13) of TCC tissues and 77\% (10 of 13) of SCBC tissues, respectively. Out of 13 matched pairs of TCC and SCBC samples, concordant methylation of RASSF1 was found in six matched pairs $(46 \%)$, and concordant lack of RASSF1 methylation was found in three matched pairs $(23 \%)$. Four matched pairs had discordant RASSF1 methylation (31\%). There was no significant difference between RASSF1 methylation frequencies in matched TCC and SCBC samples $(P=0.125)$.
Table 2 Methylation status of RASSF1, MGMT, and MLH1 in patients with coexisting TCC and SCBC

\begin{tabular}{|c|c|c|c|c|}
\hline Sample & RASSF1a & $M G M T$ & $M L H 1$ & $D A P K 1$ \\
\hline $1 \mathrm{~N}$ & M & M & & \\
\hline 1 TCC & M & M & & \\
\hline 1 SCBC & M & M & M & \\
\hline \multicolumn{5}{|l|}{$2 \mathrm{~N}$} \\
\hline 2 TCC & M & & & \\
\hline 2 SCBC & M & M & & \\
\hline \multicolumn{5}{|l|}{$3 \mathrm{~N}$} \\
\hline 3 TCC & & $\mathrm{M}$ & & \\
\hline 3 SCBC & & M & & \\
\hline $4 \mathrm{~N}$ & M & & & \\
\hline 4 TCC & & $\mathrm{M}$ & & \\
\hline \multicolumn{5}{|l|}{4 SCBC } \\
\hline $5 \mathrm{~N}$ & M & & & \\
\hline 5 TCC & $\mathrm{M}$ & $\mathrm{M}$ & & \\
\hline 5 SCBC & $\mathrm{M}$ & & & \\
\hline $6 \mathrm{~N}$ & & M & & \\
\hline 6 TCC & $\mathrm{M}$ & & & \\
\hline 6 SCBC & M & M & & \\
\hline $7 \mathrm{~N}$ & M & $\mathrm{M}$ & & \\
\hline 7 TCC & & $\mathrm{M}$ & & \\
\hline 7 SCBC & M & M & & \\
\hline $8 \mathrm{~N}$ & M & M & & \\
\hline 8 TCC & & $\mathrm{M}$ & & \\
\hline 8 SCBC & M & M & & \\
\hline $9 \mathrm{~N}$ & & M & & \\
\hline 9 TCC & & $\mathrm{M}$ & & \\
\hline 9 SCBC & M & & & \\
\hline $10 \mathrm{~N}$ & & M & & \\
\hline 10 TCC & & & & \\
\hline 10 SCBC & M & & & \\
\hline $11 \mathrm{~N}$ & M & M & & \\
\hline 11 TCC & & $\mathrm{M}$ & & \\
\hline 11 SCBC & & M & & \\
\hline $12 \mathrm{~N}$ & & $\mathrm{M}$ & & \\
\hline 12 TCC & $\mathrm{M}$ & $\mathrm{M}$ & & \\
\hline 12 SCBC & M & & & \\
\hline $13 \mathrm{~N}$ & $\mathrm{M}$ & $\mathrm{M}$ & & \\
\hline 13 TCC & M & & & \\
\hline 13 SCBC & M & M & & \\
\hline Adjacent normal & 7 & 9 & & \\
\hline Both TCC and SCBC & 6 & 5 & 0 & 0 \\
\hline TCC only & 0 & 4 & 0 & 0 \\
\hline SCBC only & 4 & 3 & 1 & 0 \\
\hline
\end{tabular}

M, methylated; N, adjacent normal tissue; SCBC, small-cell carcinoma; TCC, transitional-cell carcinoma.

MGMT methylation was observed in 69\% (9 of 13) of TCC tissues and $62 \%$ (8 of 13) of SCBC tissues, respectively. Out of 13 matched pairs of TCC and SCBC samples, concordant methylation of MGMT was found in six matched pairs (46\%), and concordant lack of MGMT methylation was found 
in one matched pair $(8 \%)$. Seven matched pairs (54\%) had discordant MGMT methylation. MGMT methylation frequency was very similar in TCC and SCBC tissues $(P=1.000)$.

Methylation of both RASSF1 and MGMT was found in $46 \%$ (6 of 13) of SCBC samples and $23 \%$ (3 of 13) of TCC samples, respectively. Methylation of both genes was more frequently harbored in SCBC only than in TCC only (6 vs 3), but this was not statistically significant $(P=0.453)$.

Using Fisher's exact test, TNM stages, gender, history of tobacco use, and age were evaluated to determine if any association with DNA methylation was present. Methylation status of RASSF1, MGMT, and of both genes was considered. No significant association between TNM stage and any methylation status was found in either TCC or SCBC.

MLH1 was only methylated in one tissue, an SCBC, which also harbored methylation of MGMT and RASSF1, whereas DAPK1 was not methylated in any tumor tissues.

To determine if field defects were involved in the carcinogenesis of SCBC, we also measured methylation levels in adjacent normal appearing tissue, which was microdissected from the original samples. RASSF1 methylation was detectable in $54 \%$ (7 of 13) of normal tissues. RASSF1 was concordantly methylated in normal tissue and at least one histopathology in 5 of these 7 patients. The concordance was not statistically significant $(P=0.453)$. MGMT methylation was detectable in $69 \%$ (9 of 13) of normal tissues. MGMT was concordantly methylated in normal tissue and at least one histopathology in 8 of these 9 patients. Again, concordance was not statistically significant $(P=0.375)$.

To determine if TCC that gives rise to SCBC is epigenetically different from TCC that does not give rise to SCBC (pure TCC), we performed the same analyses on a separate set of 14 TCC tissues from patients without SCBC. We found that RASSF1, MGMT, MLH1, and DAPK1 were methylated in 11, 1,0 , and 0 tumors within this set, respectively (Table 3). The frequency of MGMT methylation in classical TCC vs SCBC-associated TCC was statistically significantly different $(P=0.002$, Fisher's Exact Test). Other relationships were not significant.

\section{Discussion}

SCBC has a poor prognosis despite aggressive surgical and medical management. In a large series of patients with SCBC that we recently reported, outcomes were poor and survival did not appear to be influenced by whether or not the patient underwent cystectomy. ${ }^{19}$ Therefore, the diagnosis of SCBC has grave implications. It is critical to understand the molecular changes occurring in this disease in order to design better detection assays, prognostic algorithms, and therapy for patients. Epigenetic
Table 3 Methylation status of RASSF1, MGMT, and MLH1 in microdissected bladder cancer specimens containing only TCC

\begin{tabular}{lcccc}
\hline Sample & RASSF1 & MGMT & MLH1 & DAPK1 \\
\hline 14 TCC & $\mathrm{M}$ & $\mathrm{M}$ & \\
15 TCC & $\mathrm{M}$ & & \\
16 TCC & $\mathrm{M}$ & & \\
17 TCC & $\mathrm{M}$ & & \\
18 TCC & $\mathrm{M}$ & & \\
19 TCC & $\mathrm{M}$ & & \\
20 TCC & $\mathrm{M}$ & & \\
21 TCC & $\mathrm{M}$ & & \\
22 TCC & $\mathrm{M}$ & & \\
23 TCC & $\mathrm{M}$ & & \\
24 TCC & 10 & 1 & 0 \\
25 TCC & TCC & & \\
27 TCC & Sum & & & \\
\hline
\end{tabular}

M, methylated; TCC, transitional-cell carcinoma.

changes are a particularly attractive avenue to pursue because (i) they are reversible, (ii) occur in many if not all types of cancer, (iii) many molecular alterations can be targeted at once with chromatinaltering drugs, and (iv) reversing epigenetic changes is one of the few ways, if not the only way, to reactivate tumor suppressors. Additionally, several noteworthy studies have used detection of DNA methylation in urine sediment as a screening tool for several types of genitourinary cancer. ${ }^{20-22}$ Therefore, identifying epigenetic changes in SCBC may provide fruitful targets for earlier detection and novel therapies. However, few studies have described DNA methylation in SCBC. ${ }^{23,24}$ We describe the methylation status of four genes, which are commonly silenced by epigenetic mechanisms in multiple cancers.

RASSF1 is a gene with multiple transcripts, one of which encodes RASSF1A, which is transcribed from an alternate promoter. ${ }^{25}$ This gene was first identified by virtue of its location on chromosome $3 p,{ }^{25,26}$ loss of which is one of the earliest and/or most common events in lung and other cancers. ${ }^{27}$ RASSF1 resides in the minimal region of homozygous deletion in human cancers of many histologies. It functions as a bona fide tumor-suppressor gene when artificially overexpressed in cancer cells, which lack its expression. ${ }^{25}$ The mechanism of loss of function RASSF1A in cancer is almost exclusively related to deletion of $3 p$ or DNA methylationinduced silencing, as sequencing studies have shown infrequent point mutations. ${ }^{25,26}$ At this point, more is known about the mechanism of loss of RASSF1A function than about its actual function, although it is known to interact with and stabilize microtubules. ${ }^{28-31}$ Its loss in model systems is known to cause hypersensitivity to microtubuletargeting agents ${ }^{32}$ and therefore, its loss of function by methylation or deletion may herald chemosensitivity to microtubule-targeted drugs. In support of 
this theory, novel chemotherapy regimens, which include microtubule-targeting agents for TCC, are currently being explored and have shown promising results. $^{33,34}$ In addition, one case of a sustained response of SCBC to a paclitaxel-based regimen has been reported. ${ }^{35}$ In our study, $86 \%$ of patients had methylation in at least one component of their bladder tumors.

Similarly, MGMT is methylated at the gene level in a wide range of cancers including bladder cancer. ${ }^{22,36,37}$ The function of MGMT is well known: it participates in DNA repair of alkylated $O^{6}$-methylguanine, ${ }^{38,39}$ a lesion that occurs as a result of alkylation by anti-neoplastic agents. Consequently, therapeutic measures, which result in alkylation of guanine, may be effective for tumors that lack the repair mechanisms imparted by the participation of MGMT activity. Indeed, MGMT methylation is known to be a strong predictor of response to multiple alkylating agents in glioma. ${ }^{6,40}$ Therefore, agents which produce $O^{6}$-methylguanine may be a viable chemotherapeutic approach for patients with SCBC tumors in which MGMT expression has been silenced.

We found that MLH1 was infrequently methylated in the bladder tumors that we studied. MLH1 has been shown to be required for the response of tumors to cisplatin exposure in model systems. ${ }^{7,10-12}$ Platinum-based chemotherapy has been the mainstay of treatment for more than 20 years. ${ }^{41}$ TCC is often sensitive to this chemotherapy regimen, theoretically in part because its promoter is not hypermethylated and MLH1 expression is maintained. In support of this hypothesis, the lone patient with detectable MLH1 methylation survived only 3 months after being diagnosed with T2N1M1 SCBC. This patient received carboplatin and etoposide. In comparison, the eight other patients for whom survival information was available, lived an average of 15.8 months, with six of them surviving 6 months or more.

SCBC resembles small-cell lung cancer (SCLC) morphologically and clinically in terms of its propensity to metastasize, its chemoresistance, and its poor prognosis. ${ }^{42}$ Like SCBC, SCLCs frequently coexist with non-small-cell lung cancer. Smoking is the most important risk factor for the development of SCLC, as $<1 \%$ of SCLCs develop in non-smokers. Similarly, $65 \%$ of patients with SCBC had a history of smoking in the largest reported case series. ${ }^{19}$ Smoking may cause similar genetic lesions in bladder and pulmonary epithelium. MGMT and RASFF1 methylation are frequent occurrences in SCLC. ${ }^{25,43-45}$ It is notable that we observed a similar high frequency of methylation of these genes in our reported cohort of patients with SCBC.

Other studies of methylation of specific gene loci in TCC have been reported. ${ }^{23,24}$ The rate of methylation of RASSF1 that we detect in pure TCC and TCC with SCBC are similar to those in previous reports. ${ }^{37,46-49}$ However, the frequency of $M G M T$ methylation in TCC with SCBC that we observed was significantly higher than the $2-5 \%$ rates reported in two prior studies comprising 196 combined specimens of pure TCC. ${ }^{36,37}$ We believe this reflects an innate propensity for TCCs harboring MGMT methylation to develop clones of SCBC. This belief is based on the fact that we found MGMT methylation in only 1 of 14 cases containing pure TCC, but in 9 of 13 TCC samples where the histologies were admixed and genetically related. ${ }^{9}$ Our findings may distinguish MGMT methylation as an SCBC-specific epimutation. In this setting, MGMT methylation has a sensitivity of $69 \%$ and a specificity of $92 \%$ in the detection of SCBC. In contrast, DAPK1 methylation is found at higher levels $(4-25 \%)$ in pure TCCs ${ }^{36,37,49}$ compared with the tumors examined in our study, in which it was not detectably methylated in either histology. Alterations of $M L H 1$, both in primary sequence and DNA methylation, have been thoroughly explored in one study and apparently do not play a part in bladder carcinogenesis. ${ }^{50}$ Similarly, we found that methylation of MLH1 was infrequent in TCC with or without SCBC.

Urothelial carcinogenesis has been postulated to proceed through epithelium with field cancerization. ${ }^{51-54}$ To address this possibility for SCBC, we analyzed the methylation of these genes in adjacent normal appearing tissue in patients with coexisting TCC and SCBC. Methylation of MGMT and RASSF1 was detected in a majority of normal tissues. Additionally, most tumors associated with normal tissues harboring DNA methylation were also methylated at these loci. These findings suggested that methylation of a locus in normal tissue predicted methylation in the tumor sample. Our finding of epimutations in normal appearing mucosa and concordant tumor samples supports the idea that the entire epithelium may be predisposed to premalignant change. ${ }^{55}$ Tumor contamination of normal samples is possible but unlikely since these samples were carefully microdissected. Although not statistically significant, our findings do suggest a role for field cancerization through epigenetic changes.

DNA methylation studies may ultimately serve a pivotal role in the diagnosis and management of cancer. DNA methylation status is an ideal target for development of biomarkers, diagnosis, treatment, and surveillance. This study provides additional information concerning DNA methylation in smallcell carcinoma of the urinary bladder, and increases our understanding of the pathobiology of this disease.

\section{References}

1 Jones PA, Baylin SB. The fundamental role of epigenetic events in cancer. Nat Rev Genet 2002;3: 415-428. 
2 Herman JG, Baylin SB. Gene silencing in cancer in association with promoter hypermethylation. N Engl J Med 2003;349:2042-2054.

3 Li B, Carey M, Workman JL. The role of chromatin during transcription. Cell 2007;128:707-719.

4 Merlo A, Herman JG, Mao L, et al. 5' CpG island methylation is associated with transcriptional silencing of the tumour suppressor p16/CDKN2/MTS1 in human cancers. Nat Med 1995;1:686-692.

5 Herman JG, Latif F, Weng Y, et al. Silencing of the VHL tumor-suppressor gene by DNA methylation in renal carcinoma. Proc Natl Acad Sci USA 1994;91: 9700-9704.

6 Esteller M, Garcia-Foncillas J, Andion E, et al. Inactivation of the DNA-repair gene MGMT and the clinical response of gliomas to alkylating agents. N Engl J Med 2000;343:1350-1354.

7 Drummond JT, Anthoney A, Brown R, et al. Cisplatin and adriamycin resistance are associated with MutLalpha and mismatch repair deficiency in an ovarian tumor cell line. J Biol Chem 1996;271:19645-19648.

8 Laird PW. The power and the promise of DNA methylation markers. Nat Rev Cancer 2003;3:253-266.

9 Cheng L, Jones TD, McCarthy RP, et al. Molecular genetic evidence for a common clonal origin of urinary bladder small cell carcinoma and coexisting urothelial carcinoma. Am J Pathol 2005;166:1533-1539.

10 Brown R, Hirst GL, Gallagher WM, et al. hMLH1 expression and cellular responses of ovarian tumour cells to treatment with cytotoxic anticancer agents. Oncogene 1997;15:45-52.

11 Plumb JA, Strathdee G, Sludden J, et al. Reversal of drug resistance in human tumor xenografts by $2^{\prime}$ deoxy-5-azacytidine-induced demethylation of the hMLH1 gene promoter. Cancer Res 2000;60: 6039-6044.

12 Strathdee G, MacKean MJ, Illand M, et al. A role for methylation of the hMLH1 promoter in loss of hMLH1 expression and drug resistance in ovarian cancer. Oncogene 1999;18:2335-2341.

13 Eble JN, Sauter G, Epstein JI, et al. World Health Organization Classification of Tumours: Pathology and Genetics of Tumours of the Urinary System and Male Genital Organs. IARC Press: Lyon, 2004.

14 Greene FL, Page DL, Fleming ID, et al. American Joint Committee on Cancer Staging Manual. Springer: New York, 2002;367-373.

15 Cheng L, Zhang S, Wang M, et al. Molecular genetic evidence supporting the neoplastic nature of stromal cells in 'fibrosis' after chemotherapy for testicular germ cell tumors. J Pathol 2007;213:65-71.

16 Esteller M. DNA methylation and cancer therapy: new developments and expectations. Curr Opin Oncol 2005;17:55-60.

17 Eads CA, Danenberg KD, Kawakami K, et al. MethyLight: a high-throughput assay to measure DNA methylation. Nucleic Acids Res 2000;28:E32.

18 Widschwendter M, Siegmund KD, Muller HM, et al. Association of breast cancer DNA methylation profiles with hormone receptor status and response to tamoxifen. Cancer Res 2004;64:3807-3813.

19 Cheng L, Pan CX, Yang XJ, et al. Small cell carcinoma of the urinary bladder: a clinicopathologic analysis of 64 patients. Cancer 2004;101:957-962.

20 Cairns P, Esteller M, Herman JG, et al. Molecular detection of prostate cancer in urine by GSTP1 hypermethylation. Clin Cancer Res 2001;7:2727-2730.
21 Hoque MO, Begum S, Topaloglu O, et al. Quantitative detection of promoter hypermethylation of multiple genes in the tumor, urine, and serum DNA of patients with renal cancer. Cancer Res 2004;64:5511-5517.

22 Hoque MO, Begum S, Topaloglu O, et al. Quantitation of promoter methylation of multiple genes in urine DNA and bladder cancer detection. J Natl Cancer Inst 2006;98:996-1004.

23 Kunze E, Wendt M, Schlott T. Promoter hypermethylation of the 14-3-3 sigma, SYK and CAGE-1 genes is related to the various phenotypes of urinary bladder carcinomas and associated with progression of transitional cell carcinomas. Int J Mol Med 2006;18:547-557.

24 Kunze E, Von Bonin F, Werner C, et al. Transitional cell carcinomas and nonurothelial carcinomas of the urinary bladder differ in the promoter methylation status of the caveolin-1, hDAB2IP and p53 genes, but not in the global methylation of Alu elements. Int J Mol Med 2006;17:3-13.

25 Dammann R, Li C, Yoon JH, et al. Epigenetic inactivation of a RAS association domain family protein from the lung tumour suppressor locus 3p21.3. Nat Genet 2000;25:315-319.

26 Lerman MI, Minna JD. The 630-kb lung cancer homozygous deletion region on human chromosome 3p21.3: identification and evaluation of the resident candidate tumor suppressor genes. The international lung cancer chromosome 3p21.3 Tumor suppressor gene consortium. Cancer Res 2000;60:6116-6133.

27 Whang-Peng J, Kao-Shan CS, Lee EC, et al. Specific chromosome defect associated with human small-cell lung cancer; deletion 3p(14-23). Science 1982;215: 181-182.

28 Song MS, Song SJ, Ayad NG, et al. The tumour suppressor RASSF1A regulates mitosis by inhibiting the APC-Cdc20 complex. Nat Cell Biol 2004;6: 129-137.

29 Dallol A, Agathanggelou A, Fenton SL, et al. RASSF1A interacts with microtubule-associated proteins and modulates microtubule dynamics. Cancer Res 2004;64:4112-4116.

30 Liu L, Tommasi S, Lee DH, et al. Control of microtubule stability by the RASSF1A tumor suppressor. Oncogene 2003;22:8125-8136.

31 Vos MD, Martinez A, Elam C, et al. A role for the RASSF1A tumor suppressor in the regulation of tubulin polymerization and genomic stability. Cancer Res 2004;64:4244-4250.

32 van der Weyden L, Tachibana KK, Gonzalez MA, et al. The RASSF1A isoform of RASSF1 promotes microtubule stability and suppresses tumorigenesis. Mol Cell Biol 2005;25:8356-8367.

33 Bellmunt J, Guillem V, Paz-Ares L, et al. Gemcitabine/ paclitaxel-based three-drug regimens in advanced urothelial cancer. Eur J Cancer 2000;36(Suppl 2): 17-25.

34 Bellmunt J, Guillem V, Paz-Ares L, et al. Phase I-II study of paclitaxel, cisplatin, and gemcitabine in advanced transitional-cell carcinoma of the urothelium. Spanish oncology genitourinary group. J Clin Oncol 2000;18:3247-3255.

35 Matsui Y, Fujikawa K, Iwamura H, et al. Durable control of small cell carcinoma of the urinary bladder by gemcitabine and paclitaxel. Int J Urol 2002;9: 122-124.

36 Chan MW, Chan LW, Tang NL, et al. Hypermethylation of multiple genes in tumor tissues and voided urine in 
urinary bladder cancer patients. Clin Cancer Res 2002;8:464-470.

37 Maruyama R, Toyooka S, Toyooka KO, et al. Aberrant promoter methylation profile of bladder cancer and its relationship to clinicopathological features. Cancer Res 2001;61:8659-8663.

38 Ludlum DB. DNA alkylation by the haloethylnitrosoureas: nature of modifications produced and their enzymatic repair or removal. Mutat Res 1990;233: 117-126.

39 Pegg AE, Dolan ME, Moschel RC. Structure, function, and inhibition of O6-alkylguanine-DNA alkyltransferase. Prog Nucleic Acid Res Mol Biol 1995;51:167-223.

40 Paz MF, Yaya-Tur R, Rojas-Marcos I, et al. CpG island hypermethylation of the DNA repair enzyme methyltransferase predicts response to temozolomide in primary gliomas. Clin Cancer Res 2004;10:4933-4938.

41 Sternberg CN, Yagoda A, Scher HI, et al. Preliminary results of M-VAC (methotrexate, vinblastine, doxorubicin and cisplatin) for transitional cell carcinoma of the urothelium. J Urol 1985;133:403-407.

42 Blomjous CE, Vos W, De Voogt HJ, et al. Small cell carcinoma of the urinary bladder. A clinicopathologic, morphometric, immunohistochemical, and ultrastructural study of 18 cases. Cancer 1989;64:1347-1357.

43 Burbee DG, Forgacs E, Zochbauer-Muller S, et al. Epigenetic inactivation of RASSF1A in lung and breast cancers and malignant phenotype suppression. J Natl Cancer Inst 2001;93:691-699.

44 Dammann R, Takahashi T, Pfeifer GP. The CpG island of the novel tumor suppressor gene RASSF1A is intensely methylated in primary small cell lung carcinomas. Oncogene 2001;20:3563-3567.

45 Toyooka S, Toyooka KO, Maruyama R, et al. DNA methylation profiles of lung tumors. Mol Cancer Ther 2001;1:61-67.
46 Chan MW, Chan LW, Tang NL, et al. Frequent hypermethylation of promoter region of RASSF1A in tumor tissues and voided urine of urinary bladder cancer patients. Int J Cancer 2003;104:611-616.

47 Dhawan D, Hamdy FC, Rehman I, et al. Evidence for the early onset of aberrant promoter methylation in urothelial carcinoma. J Pathol 2006;209:336-343.

48 Dulaimi E, Uzzo RG, Greenberg RE, et al. Detection of bladder cancer in urine by a tumor suppressor gene hypermethylation panel. Clin Cancer Res 2004;10: 1887-1893.

49 Friedrich MG, Weisenberger DJ, Cheng JC, et al. Detection of methylated apoptosis-associated genes in urine sediments of bladder cancer patients. Clin Cancer Res 2004;10:7457-7465.

50 Furihata M, Takeuchi T, Ohtsuki Y, et al. Genetic analysis of hMLH1 in transitional cell carcinoma of the urinary tract: promoter methylation or mutation. J Urol 2001;165:1760-1764.

51 Jones TD, Wang M, Eble JN, et al. Molecular evidence supporting field effect in urothelial carcinogenesis. Clin Cancer Res 2005;11:6512-6519.

52 Davidson DD, Cheng L. Field cancerization in the urothelium of the bladder. Anal Quant Cytol Histol 2006;28:337-338.

53 Cheng L, Cheville JC, Neumann RM, et al. Natural history of urothelial dysplasia of the bladder. Am J Surg Pathol 1999;23:443-447.

54 Cheng L, Cheville JC, Neumann RM, et al. Flat intraepithelial lesions of the urinary bladder. Cancer 2000;88:625-631.

55 Lopez-Beltran A, Cheng L, Andersson L, et al. Preneoplastic non-papillary lesions and conditions of the urinary bladder: an update based on the ancona international consultation. Virchows Arch 2002;440: 3-11. 